\title{
Knowledge, attitude and practice of family planning among women of reproductive age group attending outpatient department in a tertiary centre of Northern India
}

\author{
Mahvish Qazi ${ }^{1}$, Najmus Saqib ${ }^{2 *}$, Sachin Gupta ${ }^{3}$
}

\begin{abstract}
${ }^{1}$ Department of Gynecology and Obstetrics, Government Medical College, Doda, Jammu, Jammu and Kashmir, India ${ }^{2}$ Department of Paediatrics, Government Medical College, Jammu, Jammu and Kashmir, India ${ }^{3}$ Department of Community Medicine, MM Institute of Medical Sciences and Research, Mullana, Ambala, Haryana, India
\end{abstract}

Received: 28 March 2019

Accepted: 08 April 2019

\section{*Correspondence:}

Dr. Najmus Saqib,

E-mail: shstar321@gmail.com

Copyright: () the author(s), publisher and licensee Medip Academy. This is an open-access article distributed under the terms of the Creative Commons Attribution Non-Commercial License, which permits unrestricted non-commercial use, distribution, and reproduction in any medium, provided the original work is properly cited.

\section{ABSTRACT}

Background: India with 1.35 billion people is the second most populated country in the world next to China. Total fertility rate of India is 2.2 and the current total fertility rate of Jammu and Kashmir is 1.7 which is still lagging behind various states. This study was conducted to investigate the knowledge, attitude and practices of contraception in women of reproductive age in this set up.

Methods: The present cross-sectional study was carried out in patients attending OPD (outpatient department) of Obstetrics and Gynecology at ASCOMS, Jammu, Jammu and Kashmir, India from $1^{\text {st }}$ September 2017 to $31^{\text {st }}$ August 2018. 200 married women aged between 18-49 years were included in this study. Socio-demographic characteristics of the women, their knowledge, attitude and practices on contraception were evaluated with the help of predesigned questionnaire.

Results: Out of 200 women, maximum respondents belong to age group of 21-25 years (75.6\%). Most of the contraceptive non-users belongs to age below 20 years (62.5\%). Majority of respondents were Hindu (70.37\%), maximum studied up to secondary level education (84.61\%), 70.30\% were housewives and $56.58 \%$ belongs to middle class. In $45 \%$ of respondents, media was the main source of information. Preferred spacing method was condom in $85 \%$ of cases. $68 \%$ women had knowledge of female sterilization. According to most women, family planning methods are meant for limitations of birth (43\%) and 36\% meant for spacing of birth. $80 \%$ women had positive attitude towards contraceptive usage. 50\% experienced side effects with the use of contraceptives. The most common side effect was menstrual irregularities in $25 \%$ of cases. Most common reason for not using contraceptive methods among non-respondents were lack of knowledge in $50 \%$ of cases.

Conclusions: The study showed that inspite of having good knowledge, utilization of contraceptives were less because of large family norm, religious myth, cultural and political barriers. Ignorance regarding use and side effects of various contraceptive methods is another reason for inadequate practice of family planning methods.

Keywords: Attitude, Contraception, Family planning, Knowledge, Practice

\section{INTRODUCTION}

Family Planning is defined by World Health Organization (WHO) as "a way of thinking and living that is adopted voluntarily upon the basis of knowledge, attitude and responsible decisions by individuals and couples in order to promote health and welfare of family groups and thus contribute effectively to the social development of a country, planning of parenthood is an important and most significant aspect of it. ${ }^{1}$ India was the 
first country in the world to launch the National Family Planning Programme with the aim to reduce the birth rate and stabilize population. But the uncontrolled population growth which is already exceeding 1 billion (all set to overtake China and become the most populous country in the world by 2045) still remains the single greatest threat to the political, economic and social development of the country. ${ }^{2}$ The family planning programme was initiated with a very cautious approach in India after the independence (1952), natural method of family planning was considered to be the most appropriate technique for limiting births but a major breakthrough in contraceptive technology occurred when intrauterine device known as the 'Lippes Loop' was accepted in India in 1965, the government started promoting the device through intensive campaigns. Of the world population, $75 \%$ live in developing countries characterized by high fertility rate, high maternal and infant mortality rate and low life expectancy. ${ }^{3}$ Each year approximately 55,000 women die in India due to pregnancy or childbirth-related complications. ${ }^{4}$ According to NFHS-3 around $30 \%$ of the fertility in India was unwanted, indicating a huge gap between the demand and supply of family planning measures and the unmet need for the country as a whole is about $13 \%$. The unmet need is high among married women aged 15-19 years (25\% for spacing and $2 \%$ for limiting) and among those aged 20-24 years (15\% for spacing and over $6 \%$ for limiting).$^{5-7}$ Estimates derived from data from the WHO predict that at prevailing rates, one in five women in developing countries will be hospitalized for complications of unsafely performed abortion at some time in their lives. ${ }^{8}$ Most abortionrelated maternal deaths are attributable to illegal abortions hence contributing $8 \%$ to the cause of maternal mortality ratio in India. ${ }^{9,10}$ Globally, the prevalence of contraceptive use has been increasing but the unmet need for contraception still remains a problem. ${ }^{11}$ The essential aim of family planning is to prevent the unwanted pregnancies. A proper family planning can reduce the maternal mortality by reducing the number of pregnancies, abortions and the proportions of births at risk. Keeping this in mind this cross-sectional study was carried out to assess the knowledge, attitude and practices of contraceptives in this set up.

\section{METHODS}

The present study was a cross-sectional observational study that is carried out in ASCOMS, Jammu, Jammu and Kashmir, India from $1^{\text {st }}$ September 2017 to $31^{\text {st }}$ August 2018. 200 married women aged between 18-49 years were interviewed. Along with the sociodemographic characteristics of the women, their knowledge, attitude and practices on contraception were evaluated with the help of predesigned questionnaire. The dependent variables were awareness, attitude, practices and preference contraceptive methods. Independent variables were age, religion, education level, occupation, socioeconomic status, age at marriage, number of pregnancies, number of living children, source of information. Questionnaire also enquired about source of knowledge regarding contraception whether they obtained from media, health worker, social circle, family members, friends etc.

\section{Inclusion criteria}

All married women in the reproductive age group (18-49 years) who have attended the gynecology OPD (outpatient department) during the study period were selected as study subjects.

\section{Exclusion criteria}

- Unmarried women,

- Women who have undergone hysterectomy,

- All women in antenatal period,

- Women in post-partum period,

- Women in menopause,

- Women not willing to participate.

\section{RESULTS}

Among 200 women of reproductive age group maximum respondents belong to age group 21-25 years (75.6\%). Most of the contraceptive non-users belongs to age below 20 years $(62.5 \%)$. Among respondent's majority were Hindus $(70.37 \%)$. Majority of the women studied up to secondary level education (84.61\%) and the contraceptive usage increases with increasing educational status. Use of contraception is $76.92 \%$ with primary level education, $79.54 \%$ with middle, $84.61 \%$ with secondary and 87.23 with higher studies whereas only $44.44 \%$ contraceptive usage seen among illiterate group. Majority were housewives $(70.30 \%)$ in this study and percentage of non-users were also high $(29.70 \%)$ among housewives. Majority of respondents belongs to urban areas (71.03\%) and middle class $(56.58 \%)$. Among lower class $74.73 \%$ respondents were non-contraceptive users. With increasing class, contraceptive usage found increased i.e. $100 \%$ with upper class. Contraceptive usage is highest with women who married before 18 years $(80 \%)$ and women whose married life was of duration more than 7 years as they completed their family $(65.38 \%)$. Contraceptive use was also high $(80.64 \%)$ among women with children $\geq 1$ (Table 1). Among 200 respondents 188 (94\%) women heard about family planning, $45 \%$ respondent's media is the source of information followed by friends/relatives/internet which is $15 \%$. $10 \%$ women got knowledge about family planning methods from health professionals. Among the temporary methods, condom is the well-known method $(85 \%)$ and second most is oral contraceptives $72 \%$ followed by intrauterine devices (59\%). Only 3\% women knew about injectables. Among permanent methods, $68 \%$ women had knowledge of female sterilization. According to most of the women, family planning methods were meant for limitations of birth (43\%) and 36\% meant for spacing of birth while for $3.5 \%$ women meant for both limitation and spacing of birth. Among respondents $65 \%$ women knew that family 
planning methods also prevents from STDs while $8 \%$ knew it help in improvement of health and $9.5 \%$ knew that it protects from cancer. $17.5 \%$ women had no idea regarding non-contraceptive benefits of family planning (Table 2).

Table 1: Socio-demographic profile the subjects.

\begin{tabular}{|c|c|c|c|c|c|}
\hline \multirow{2}{*}{$\begin{array}{l}\text { Socio-demographic profile } \\
\text { Age in years }\end{array}$} & \multirow[t]{2}{*}{ No. of subjects } & \multicolumn{2}{|l|}{ User } & \multicolumn{2}{|c|}{ Non-User } \\
\hline & & No. & $\%$ & No. & $\%$ \\
\hline $18-20$ & 8 & 3 & 37.5 & 5 & 62.5 \\
\hline $21-25$ & 82 & 62 & 75.6 & 20 & 24.4 \\
\hline $26-30$ & 68 & 46 & 67.65 & 22 & 32.35 \\
\hline$>30$ & 42 & 31 & 73.8 & 11 & 26.2 \\
\hline \multicolumn{6}{|l|}{ Educational level } \\
\hline Illiterate & 18 & 8 & 44.44 & 10 & 55.56 \\
\hline Primary & 13 & 10 & 76.92 & 3 & 23.08 \\
\hline Middle & 44 & 35 & 79.54 & 9 & 20.46 \\
\hline Secondary & 78 & 66 & 84.61 & 12 & 15.39 \\
\hline Graduate+ & 47 & 41 & 87.23 & 6 & 12.77 \\
\hline \multicolumn{6}{|l|}{ Occupation } \\
\hline Housewife & 165 & 116 & 70.30 & 49 & 29.70 \\
\hline Unskilled worker & 5 & 4 & 80 & 1 & 20 \\
\hline Professional & 30 & 27 & 90 & 3 & 10 \\
\hline \multicolumn{6}{|l|}{ Religion } \\
\hline Hindu & 135 & 95 & 70.37 & 40 & 29.63 \\
\hline Muslim & 39 & 25 & 64.10 & 14 & 35.90 \\
\hline Sikh & 17 & 10 & 58.82 & 7 & 41.18 \\
\hline Christian & 9 & 5 & 55.56 & 4 & 44.44 \\
\hline \multicolumn{6}{|l|}{ Residence } \\
\hline Rural & 55 & 37 & 67.27 & 18 & 32.73 \\
\hline Urban & 145 & 103 & 71.03 & 42 & 28.97 \\
\hline \multicolumn{6}{|l|}{ Socioeconomic status } \\
\hline Upper & 2 & 2 & 100 & 0 & 0 \\
\hline Middle & 76 & 43 & 56.58 & 33 & 43.42 \\
\hline Lower middle & 10 & 6 & 60 & 4 & 40 \\
\hline Upper lower & 21 & 7 & 33.33 & 14 & 66.67 \\
\hline Lower & 91 & 23 & 25.27 & 68 & 74.73 \\
\hline \multicolumn{6}{|l|}{ Age at marriage (years) } \\
\hline$<18$ & 10 & 8 & 80 & 2 & 20 \\
\hline $18-25$ & 167 & 113 & 67.66 & 54 & 32.34 \\
\hline$>25$ & 23 & 15 & 65.22 & 8 & 34.78 \\
\hline \multicolumn{6}{|l|}{ Duration of marriage } \\
\hline$\leq 1$ & 18 & 9 & 50 & 9 & 50 \\
\hline $2-4$ & 41 & 30 & 73.17 & 11 & 26.83 \\
\hline $5-7$ & 63 & 42 & 66.67 & 21 & 33.33 \\
\hline$>7$ & 78 & 51 & 65.38 & 27 & 34.62 \\
\hline \multicolumn{6}{|l|}{ No. of pregnancy } \\
\hline 0 & 8 & 2 & 25 & 6 & 75 \\
\hline 1 & 33 & 12 & 36.36 & 21 & 63.64 \\
\hline 2 & 64 & 49 & 76.56 & 15 & 23.44 \\
\hline$\geq 3$ & 95 & 73 & 76.84 & 12 & 23.16 \\
\hline \multicolumn{6}{|l|}{ No. of living children } \\
\hline 0 & 16 & 5 & 31.25 & 11 & 68.75 \\
\hline 1 & 31 & 25 & 80.64 & 6 & 19.36 \\
\hline 2 & 116 & 79 & 68.10 & 37 & 31.90 \\
\hline$\geq 3$ & 37 & 23 & 62.16 & 14 & 37.84 \\
\hline
\end{tabular}


Table 2: Knowledge and awareness regarding family planning methods.

\begin{tabular}{|lll|}
\hline Knowledge and awareness & Number & Percentage \\
\hline Heard about family planning & 188 & 94 \\
\hline Source of information & & 45 \\
\hline Media & 90 & 7 \\
\hline Magazines & 14 & 15 \\
\hline Internet & 30 & 15 \\
\hline Friends/Relatives & 30 & 10 \\
\hline Health professionals & 20 & 2 \\
\hline Others & 4 & 85 \\
\hline Contraceptive methods known & & 72 \\
\hline Condom & 170 & 59 \\
\hline Oral contraceptive pills & 144 & 3 \\
\hline Intrauterine devices & 118 & 62.5 \\
\hline Injectables & 6 & 68 \\
\hline Natural methods & 125 & 44.5 \\
\hline Female sterilization & 136 & 3 \\
\hline Male sterilization & 89 & 85 \\
\hline No idea & 6 & 15 \\
\hline Awareness of emergency contraception & & \\
\hline Yes & 170 & 43 \\
\hline No & 30 & 36 \\
\hline Concept regarding family planning & & 4.5 \\
\hline Limitation of births & 86 & 3.5 \\
\hline Spacing of births & 72 & 13 \\
\hline Stopping birth & 9 & 65 \\
\hline Limitation of birth and spacing of birth both & 7 & 8.5 \\
\hline No idea & 26 & 17.5 \\
\hline Knowledge of non-contraceptive benefits of family planning methods & \\
\hline Prevention from STD & 130 & \\
\hline Improvement of health & 16 & \\
\hline Protection against cancer & 19 & 35 \\
\hline No idea & & \\
\hline & & \\
\hline
\end{tabular}

Table 3: Attitude towards use of family planning methods.

\begin{tabular}{|lcl|}
\hline Would practice family planning methods or encourage others & No. 200 & Percentage \\
\hline Yes & 160 & 80 \\
\hline No & 40 & 20 \\
\hline Will adopt family planning methods (If not using currently & No. 65 & Percentage \\
\hline Yes & 49 & 75.4 \\
\hline No & 16 & 24.6 \\
\hline Type of method & 32 & 65.3 \\
\hline Condom & 8 & 16.3 \\
\hline Oral contraceptive pills & 5 & 10.2 \\
\hline Intrauterine contraceptive device & 0 & 0 \\
\hline Injectables & 1 & 2 \\
\hline Natural method & 2 & 4.1 \\
\hline Female sterilization & 1 & 2 \\
\hline Male sterilization & & \\
\hline
\end{tabular}

Among 200 respondents, 80\% women had positive attitude towards contraceptive usage, and they would like to encourage others also for contraceptive usage. Among non-contraceptive users, $75.4 \%$ women had positive 
attitude to adopt family planning methods while $24.6 \%$ women still did not want.

Among temporary methods, $65.3 \%$ women would like to use condom and $16.3 \%$ women choose OCPs and $10.2 \%$ preferred intrauterine devices. $4.1 \%$ women choose female sterilization and $2 \%$ male sterilization (Table 3 ).

Table 4: Use of family planning methods in the past.

\begin{tabular}{|lll|}
\hline Used in the past & No. 200 & $\%$ \\
\hline Yes & 120 & 60 \\
\hline No & 80 & 40 \\
\hline Contraceptive used in past & No. 120 & \% \\
\hline Condom & 79 & 65.8 \\
\hline OCPS & 21 & 17.5 \\
\hline IUCDS & 20 & 16.7 \\
\hline Injectables & 0 & 0 \\
\hline Female sterilization & 0 & 0 \\
\hline Male sterilization & 0 & 0 \\
\hline Others & 0 & 0 \\
\hline Reason for using them & No. 120 & \% \\
\hline Easily available & 83 & 69.2 \\
\hline Comfortable and easy to use & 77 & 64.2 \\
\hline Inexpensive & 4 & 3.33 \\
\hline Husband's choice & 60 & 50 \\
\hline Others & 3 & 2.5 \\
\hline Reasons precluding women to & $\mathbf{N o . ~ 8 0}$ & $\mathbf{\%}$ \\
\hline practice contraceptives & & 50 \\
\hline Lack of knowledge & 40 & 13.8 \\
\hline Pressure from husband & 11 & 12.5 \\
\hline Desire for son & 10 & 11.3 \\
\hline Prohibition by religion & 9 & 3.7 \\
\hline Fear of side effects & 3 & 2.5 \\
\hline Pressure from mother in law & 2 & 6.2 \\
\hline Non availability & 5 & \\
\hline & & 0 \\
\hline
\end{tabular}

Among 200 respondents, $120(60 \%)$ women had used contraceptives in past. $65.8 \%$ women were using condom, $17.5 \%$ were using OCPs followed by IUCDs $(16.7 \%) .69 .2 \%$ women choose family planning methods because they were easily available while $64.2 \%$ women found it comfortable and easy to use. In $50 \%$ of women, the choice of method was decided by husband.

Barrier to using contraceptives- $50 \%$ women not practicing any family planning methods because of lack of knowledge, $13.8 \%$ due to pressure from husband, $12.5 \%$ due to desire for a male child, $11.3 \%$ thought it to be against religion, $6.2 \%$ due to non- availability as they were from rural area, $3.7 \%$ women not using any contraceptive methods because of fear of side effects and $2.5 \%$ not using due to pressure from mother-in-law for a male child (Table 4).

Among the 200 contraceptive users, $100 \quad(50 \%)$ experienced side effects with the use of contraceptives. The most common side effects were menstrual irregularities $50(25 \%)$ followed by change in weight 20 (10\%) (Table 5).

Table 5: Frequency of side effects with the use of contraceptives.

\begin{tabular}{|lll|}
\hline Side effect & Frequency & $\%$ \\
\hline No side effects & 100 & 50 \\
\hline Menstrual disturbances & 50 & 25 \\
\hline Change in weight & 20 & 10 \\
\hline $\begin{array}{l}\text { Other effects (infections, } \\
\text { backache, feeling of guilt, etc. }\end{array}$ & 16 & 8 \\
\hline Behavioral disturbances & 14 & 7 \\
\hline
\end{tabular}

\section{DISCUSSION}

In the present study, most of the women (75.6\%) belong to the age group of 21-25 years. A study conducted by Kumari L et al, also observed that most of the women fall in the age group of $21-30$ years. ${ }^{12} 84.61 \%$ respondents studied up to secondary school and only $44.44 \%$ were illiterate. This figure is consistent to study conducted by Ullah $\mathrm{I}$ et al, and Tuladhar $\mathrm{H}$ et al, where most of the respondants were literate. ${ }^{13,14}$ Tuladhar $\mathrm{H}$ et al, also observed in their study that when women's education was of secondary or higher level, awareness was $100 \% .^{14}$ Present study revealed that in majority of the cases the source of information was media $(45 \%)$ followed by internet/friends and relatives $(15 \%)$ and health professionals $(10 \%)$ which is in consistent with a study conducted in Kanpur by Jahan $\mathrm{U}$ et al, Tuladhar $\mathrm{H}$ et al, and Mustafa $\mathrm{R}$ et al, in Karachi and international study from Nigeria whereas in Srivastava $\mathrm{R}$ et al, study they found $70 \%$ had gained knowledge of contraception from friends and relatives and 39\% from TV and radio. ${ }^{14-18}$

In the present study, $94 \%$ of the subjects were aware of one or more methods of contraception which is in consistent with the earlier reports of $95.2 \%, 97.7 \%$ and $100 \%{ }^{19-21}$ The results also are similar to the international study by Abasiattai A et al, from Nigeria where $87.6 \%$ cases and by Tuladhar $\mathrm{H}$ et al, from Nepal where $93 \%$ cases knew about contraceptive methods. ${ }^{14,22}$ However, contrast studies in KSA and in Jordan showed a low level of knowledge regarding the contraceptive usage. ${ }^{23,24}$ However, low awareness about contraceptives has also been reported in various parts of India i.e., 52.4\% and $42.4 \% .^{25,26}$ According to Park HJ et al, the older the women, the more frequently they were exposed to family planning methods. ${ }^{27}$ Mohanan $\mathrm{P}$ et al, also highlighted that acceptors of contraception were of higher age and parity. ${ }^{28}$ In this study, author found contraceptive usage increases with increase in literacy, $76.92 \%$ contraceptive usage was seen in primary, 79.54 in middle, 84.61 in secondary educated women and 87.23 with higher studies. Only $44.44 \%$ contraceptive usage was seen in illiterate women. Similar results were found in study conducted at Kanpur, they found $69.6 \%$ contraceptive usage in secondary and higher educated women and $62.6 \%$ in primary educated women. ${ }^{15}$ In other study, 
Gautam AC et al, found that raise in education status helps in improving acceptance of contraceptive practices. $^{29}$

Contraception usage was more in Urban population (71.03\%) compared to Rural population. About 70-80\% of women with 1 or more than 1 living child were using contraception in comparison to $31.25 \%$ by those having no living issues. Jahan $\mathrm{U}$ et al, had also shown that $77.5 \%$ of women with 3 or more living issues were used contraceptive methods as compared to $35 \%$ of those having no live issues. ${ }^{15}$

Lasse A et al, had also shown that women with 3 or more living children are more likely to use contraception than if they had 2 or less. ${ }^{30}$ Positive correlation was observed between age, parity, female occupation, education and contraceptive practices which is similar to other Pakistani study. ${ }^{31}$ Husband education is the most dominant determinant for the use of contraceptive in the work of others, having more sons was another important cause for the non-users as also reported by others, religion has been identified to play a significant role in decision to use contraception. ${ }^{32,33}$ Muslims tend to have higher disapproval rate for contraception. ${ }^{34}$ Therefore, religious scholars should be involved to make it clear that family planning is not sinful and rather beneficial to them. The contraceptive usage in this study was $80 \%$.

Regarding the usage of family planning methods, an important dimension is the type of family planning method used. Among the temporary methods, condoms $(85 \%)$ was most known method followed by oral contraceptives (72\%) and IUCDs (59\%) similar to the study conducted by Jahan U et al, where $74.8 \%$ subjects know about OCPs, $68.8 \%$ about condoms followed by IUCDs $(56.6 \%)$ and injectables $(38.4 \%) .{ }^{15}$ While in Gupta V et al, study female sterilization (45.6\%) was the most chosen method followed by IUCDs (23\%) and condoms $(22 \%)$, the least preference was given to OCPs $(9.2 \%) .{ }^{35}$ Abasiattai $\mathrm{A}$ et al, found male condoms to be the most used method (40.4\%) while Tuladhar $\mathrm{H}$ et al, found the most used method in their study was depo provera. ${ }^{14,24}$

In contrast, study conducted by Jabeen $\mathrm{M}$ et al, commonly used methods were traditional, injectable and female sterilization which is different from the work of Lata $\mathrm{K}$ et al, who observed the IUCD as most widely used method. ${ }^{36,37}$ The difference is because factors like choice of contraceptive method, availability, source of information, government policies which vary from place to place. In this study, $3 \%$ were not aware of any method of contraception nearby results were found in study conducted by Jahan $\mathrm{U}$ et al, where $8.79 \%$ women were not aware of any form of contraception. ${ }^{15}$

In permanent methods, these results showed that most of the women $(68 \%)$ had heard about female sterilization as compared to $(44.5 \%)$ about male sterilization. Jahan U et al, also found female sterilization (36.4\%) as most known method in comparison to male sterilization i.e., $25.3 \% .^{15}$

In Gupta $\mathrm{V}$ et al, they also reported female sterilization as most chosen method (95.6\%) and male sterilization $(89.6 \%) .{ }^{38}$ Kumari L et al, and Saima Nazir et al, also reported the female sterilization as the most widely used method. ${ }^{12,39}$ This disparity may be because of common belief that reproduction is mainly the function of women. Attitudes are not gained by birth, they are learned and adopted by experiences and culturally gained during socialization. Attitudes of women towards family planning are influenced by education and their past experiences of contraceptives. In this study, $80 \%$ women has shown positive attitude towards contraception usage which is a bit higher than a study conducted in TEZU village, Manipal, India where majority $60 \%$ had positive attitude. In this study, $24.6 \%$ women had not adopted any type of family planning method as compared to $37.1 \%$ in Renjhen Prachi et al, where $44.6 \%$ of women had never used any contraceptive method in Sikkim in 2005..$^{40}$

In this study, $60 \%$ women had used at least one method of contraception, condom was most preferred method i.e. $65.8 \%$ followed by OCP's $17.5 \%$ and IUCDs $16.7 \%$. $69.2 \%$ women choose at least one contraceptive method because they were easily available. 50\% women not using any type of contraceptive method because of lack of knowledge, $12.5 \%$ women had desire to have a male child. Similar result was found in Jahan U et al, where $32.1 \%$ stopped using contraceptive methods due to various reasons like due to lack of knowledge in $42.4 \%$, $60.55 \%$ desire to have next child. ${ }^{15}$ A study conducted in Iraq also revealed that the main reason for not using contraceptives were side effects $(44.4 \%)$, followed by the desire to have children as stated by $23.2 \%$ of the respondents and other reasons were husband objection, cost of contraceptives and religious beliefs respectively. ${ }^{41}$ Lavanya KS et al, in their study noted that the reasons for not using contraception included non-reliability, lack of knowledge, partner opposition, willing to have more children and fear of side effects. ${ }^{12}$ Fear of side effects of contraceptives was one of the major reasons for nonpractice of contraception observed and seen in other studies as well. ${ }^{42}$

The study suffers from the usual limitation of a crosssectional study. author could not include the most vulnerable group the young unmarried girls as we can also not guarantee about the honest answers as it covered the sensitive issue i.e. sex and recall bias but maintaining the privacy, author could extract most of the information. Also, this study was limited to women and that information about men was collected from their wives indirectly although men comprise the decision-making component in country like India who need to be educated before if we want a new contraceptive method to be successful. As it is a cross-sectional study it could be difficult to establish cause and effect relationship between the variables and study was conducted in certain 
cantonment of displaced population so finding cannot be generalized to overall population.

\section{CONCLUSION}

In this study, author observed that with increasing educational and socioeconomic status contraceptive practices is increasing. Author found that awareness towards the family planning methods are good but contraceptive practices are poor because of lack of knowledge and fear of side effects. Various studies conducted all over India have shown that men and women are aware of various methods of contraception, but timely knowledge is lacking especially during initial years of marriage. This incomplete and inadequate information of contraception may lead to non- acceptance of family planning methods and may be associated with unmet need of contraception.

Special attention should be placed on reaching younger women, on adult education program, informational approaches aimed at both sexes especially in rural areas. In addition, sex and family education should be imparted from school years. One of the possible drawbacks of family planning programmes is that men are usually excluded from the programme even when they are still major decision makers in the majority of households. Religious scholars must play their responsibility in clarifying many aspects regarding contraceptives.

\section{Recommendations}

Education of the community on importance of having smaller families and empowerment of women should be intensified. Encouraging gender balance by changing community attitude towards position/status of women in a household and in a society as a whole should be strengthened. This would improve their participation in household decisions including those related to fertility and contraceptive use. Increase in community campaigns to raise awareness on importance of modern contraceptives among males (husbands) should be emphasized and should go along with those involving women.

Future researchers should carry out similar research among women attending post-natal clinics in private hospitals and those attending traditional birth attendant homes. Comparative analysis could be carried out to measure their variance.

\section{ACKNOWLEDGMENTS}

Authors would like to thank faculty of the Gynecology and Obstetrics, ASCOMS, Jammu, Jammu and Kashmir, India and colleagues for their support during study.

Funding: No funding sources

Conflict of interest: None declared
Ethical approval: The study was approved by the Institutional Ethics Committee

\section{REFERENCES}

1. Park K. Demography and family planning. Text book of preventive and social medicine, $21^{\text {st }}$ Ed: Jabalpur, $\mathrm{M} / \mathrm{s}$ Banarsidas Bhanot Publishers; 2011:443,445,447,454.

2. Patil MG, Mahyavanshi DK, Kartha G. A cross sectional study on KAP regarding spacing methods among married women of the reproductive age group in the field practice area of UHTC in Surrendranagar district, Healthline. 2011;2(2):31-5.

3. Population Reference Bureau. World Population Data Sheet, 2010. Available at: http://www.prb.org/pdf10/10wpds_eng.pdf.

4. Rai SK, Dasgupta R, Das MK, Singh S, Devi R, Arora NK. Determinants of utilization of services under MMJSSA scheme in Jharkhand 'client perspective's: a qualitative study in a low performing state of India. Ind J Pub Health. 2011;55:252-9.

5. Weldegerima B, Denekew A. Women's knowledge, preferences, and practices of modern contraceptive methods in Woreta, Ethiopia. Res Social Administrative Pharmacy. 2008;4(3):302-7.

6. Bhasin K, Pant M, Mehta M, Kumar S. Prevalence of usage of different contraceptive methods in East Delhi- a cross sectional study. Indian J Comm Med. 2005;30:52-5.

7. Mahawar P, Anand S, Raghunath D, Dixit S. Contraceptive knowledge, attitude and practices in mothers of infant: a cross-sectional study. Natl J Community Med. 2011;2:105-7.

8. Singh S. Hospital admissions resulting from unsafe abortion: estimates from 13 developing countries. Lancet. 2006;368(9550):1887-92.

9. Maharana B. Correlates of Spontaneous and Induced Abortion in India: an investigation using a nationwide large scale survey data. Int Inst Popul Sci. 2011.

10. MOHFW. A handbook for the state investment programme managers \& ECTA facilitators \& consultants. In: MOHFW, eds. Sector Investment Programme (supported by EC). New Delhi: Ministry of Health \& Family Welfare. Government of India and European Commission; 2000.

11. Alkema L, Kantorova V, Menozzi C, Biddlecom A. National, regional, and global rates and trends in contraceptive prevalence and unmet need for family planning between 1990 and 2015: a systematic and comprehensive analysis. Lancet. 2013;381(9878):1642-52.

12. Sarella LK, Prasanna NS. A study on contraceptive knowledge, attitude and practice among reproductive age group women in a tertiary institute. Int J Heal Sci Res. 2014 Apr;10(2):577-80.

13. Inamullah H, Sarwar M, Khan N, Hifazatullah NM, Hussain I. Attitude of Religious Class toward 
contemporary female higher education. Inter Business Economic Res J. 2010;9:11-6.

14. Tuladhar H, Marahatta R. Awareness and practice of family planning methods in women attending gyne OPD at Nepal Medical College Teaching Hospital. Nepal Med Coll J. 2008;10(3):184-91.

15. Jahan U, Verma, Gupta S, Gupta R, Mahour S, Kirti $\mathrm{N}$ et al. Awareness, attitude and practices of family planning methods in a tertiary care hospital. Uttar Pradesh, India, Int. J Report Contracept Obstet Gynecol. 2017;6:500-6.

16. Mustafa R, Afreen U, Hashmi HA. Contraceptive knowledge, attitude and practice among rural women. J Coll Physicians Surg Pak. 2008;18(9):5425.

17. Obisesan KA, Adeyemo AA, Fakokunde BO. Awareness and use of family planning methods among married women in Ibadan, Nigeria. East African Med J. 1998;75(3):135-8.

18. Srivastava R, Srivastava DK, Jina R, Srivastava K, Sharma N, Sana S. Contraceptive knowledge, attitude and practice (KAP Survey). J Obstet Gynecol India. 2005;55(6):546-0.

19. Manjeera LM, Neetha SR. Contraceptive practices among reproductive age group of women in Justice KS Hegde Medical College Hospital, Mangalore. Int J Reprod Contracept Obstet Gynecol. 2013;2(1):3946.

20. National family health survey-3(NFHS-3), 2005-06, volume-1, international institute for population sciences, Deonar, Mumbai, Ministry of Health And Family Welfare, GOI.

21. Takkar N, Goel P, Saha PK, Dua D. Contraceptive practices and awareness of emergency contraception in educated working women. Ind $\mathrm{J}$ Med Sci. 2005;59(4):143-9.

22. Abasiattai AM, Etukumana E, Utuk NM, Umoiyoho A. Awareness and practice of contraception among antenatal attendees in a tertiary hospital in southsouth Nigeria. TAF Preventive Medicine Bulletin. 2011;10(1):29-34.

23. Al Sheeha M. Awareness and use of contraceptives among saudi women attending primary care centers in Al-qassim, saudi arabia. Int $\mathbf{J}$ Heal Sci. 2010;4(1):11.

24. Mahadeen AI, Khalil AO, Hamdan-Mansour AM, Sato $\mathrm{T}$ and Imoto A. Knowledge, attitudes and practices towards family planning among women in the rural southern region of Jordan. Eastern Mediterranean Heal J. 2012;18:567-72.

25. Patil SS, Durgawale MP, Patil SR. Epidemiological correlates of unmet need for contraception in urban slum population. Al Ameen $\mathrm{J}$ Med Sci. 2010;3(4):312-6.

26. Prateek SS, Saurabh RS. Contraceptive practices adopted by women attending an urban health centre. African Heal Sci. 2012;12(4):416-21.

27. Park HJ, Chung KK. Differential Effects of Communication Media on Family Planning
Behavior. Korean J Preventive Med. 1975;8(1):3752.

28. Mohanan P, Kamath A, Sajjan BS. Fertility pattern and family planning practices in a rural area in Dakshina Kannada. Ind J Comm Med. 2003;28(1):15.

29. Gautam AC, Seth PK. Appraisal of the Knowledge, Attitude and Practices (KAP) of Family Control Devices Among Rural Rajputs and Scheduled Caste of Hatwar Area of Bilaspur District, Himachal Pradesh, India. Anthropol. 2002;4(4):289-92.

30. Lasee A, Mccormic JB. Demographic and socioeconomic determinants of contraceptive use in a low income community of Karachi. J Pakistan Med Assoc. 1996;46:228-31.

31. Ali S, Rozi S, Mahmood MA. Prevalence and factors associated with practice of modern contraceptive methods among currently married women in District Naushahro Feroze. J. Pak Med Assoc. 2004;54(9):461.

32. Saxena S, Oakeshott P, Hilton S. Contraceptive use among South Asian women attending general practices in southwest London. Br J Gen Pract. 2002;52(478):392-4.

33. Khan T, Ali Khan RE. Fertility behaviour of women and their household characteristics: A case study of Punjab, Pakistan. J Human Ecol. 2010;30(1):11-7.

34. Ibrahim MT, Sadiq AU. Knowledge, attitude, practices and beliefs about family planning among women attending primary health care clinics in Sokoto, Nigeria. Niger J Med. 1999;8(4):154-8.

35. Gupta V, Mohapatra D, Kumar V. Family planning knowledge, attitude, and practices among the currently married women (aged 15-45 years) in an urban area of Rohtak district, Haryana. Int J Med Sci Pub Heal. 2016;5(4):627-33.

36. Jabeen M, Gul F, Wazir F, Javed N. Knowledge, attitude and practices of contraception in women of reproductive age. Gomal J Med Sci. 2011;9(2):223.

37. Lata K, Barman SK, Ram R, Mukherjee S, Ram AK. Prevalence and determinants of unmet need for family planning in Kishanganj district, Bihar, India. GJMEDPH. 2012;1(4):29-32.

38. Gupta V, Mohapatra D, Kumar V. Family planning knowledge, attitude, and practices among the currently married women (aged 15-45 years) in an urban area of Rohtak district, Haryana. Int J Med Sci Pub Heal. 2016;5:627-632.

39. Nazir S, Mittal A, Anand BK, Goel RKD, Singh J, Rashid A. Determinants of unmet need for family planning in a developing country: an observational cross-sectional study. Natl J Community Med. 2015; 6(1):86-91.

40. Renjhen P, Gupta SD, Barua A. A study of knowledge, attitute and practice of family planning among the women of reproductive age group in Sikkim. J Obstet Gynecol India. 2008;58:63-7.

41. Ebrahim S, Muhammed N. Knowledge, Attitude and Practice of family planning among women in Basrah city South of Iraq. MBU. 2011;29:(1,2):70-6. 
42. Grossman D, Fernandez L, Hopkins K, Amastae J, Potter JE. Perceptions of the safety of oral contraceptives among Latin population. Contraception. 2010;81:254-60.
Cite this article as: Qazi M, Saqib N, Gupta S.

Knowledge, attitude and practice of family planning among women of reproductive age group attending outpatient department in a tertiary centre of Northern India. Int J Reprod Contracept Obstet Gynecol 2019;8:1775-83. 